\title{
Differences in achieving treatment goals with statin use in various regions of Poland - 3ST-POL study results
}

\author{
Daniel Śliż ${ }^{1,2}$, Krzysztof J Filipiak ${ }^{3}$, Marek Naruszewicz ${ }^{4}$, Janusz Siebert ${ }^{5}$, Artur Mamcarz ${ }^{1}$ \\ 1 3rd Department of Internal Medicine and Cardiology, Medical University of Warsaw, Poland \\ 2 Public Health School, Centre of Postgraduate Medical Education, Poland \\ ${ }^{3}$ 1st Department of Cardiology, Medical University of Warsaw, Poland \\ ${ }^{4}$ Department of Pharmacognosy and Molecular Basis of Phytotherapy, Medical University of Warsaw, Poland \\ ${ }^{5}$ Department of Family Medicine. Medical University of Gdansk, Poland
}

Śliż D, Filipiak KJ, Naruszewicz M, Siebert J, Mamcarz A. Differences in achieving treatment goals with statin use in various regions of Poland - 3ST-POL study results. Ann Agric Environ Med. 2016; 23(1): 116-119. doi: 10.5604/12321966.1196865

\section{Abstract}

Introduction and objective. Dyslipidemia is the most common factor leading to ischemic heart disease, which is one of the leading causes of death. The use of statins is the most important preventative measure of ischemic heart disease; however, their efficacy in patients in Poland is still too low. The purpose of this study was to evaluate regional differences in achieving treatment goals in total cholesterol (TC) and LDL cholesterol levels in patients treated with statins on an outpatient basis. Materials and methods. A survey was used to evaluate efficacy of treatment, completed by 49,950 patients in Poland treated with statins in 2008. The territory of Poland was divided into 4 research regions: the Northeast (NE), Northwest (NW), Southeast (SE), and Southwest (SW) regions.

Results. The largest group of patients resided in the SW region, the smallest in the SE region. Participants of the study suffered from hypercholesterolemia, on average, for at least a year before completing the study survey. Effective treatment leading to achievement of target TC was observed in less than $10 \%$ of the patients. Rate of achievement of target cholesterol levels was highest in the NE region, lowest in the NW region. Cardiologists were more successful in achieving therapeutic goals than GPs. Similar correlations between regions and doctors' specializations were observed for LDL values.

Conclusions. Significant differences in the efficacy of treatment with statins were observed among the study group and were evaluated based on achievement of target TC and LDL cholesterol levels. Better results achieved in the NE region may be because the region includes the Masovian province, which is the most economically developed region in Poland.

\section{Key words}

dyslipidemia, statins, ischemic heart disease

\section{INTRODUCTION}

Ischemic heart disease and its complications are the most common causes of death among populations in developing countries, including Poland [1]. According to epidemiological studies conducted in Poland in the last decade, such as the WOBASZ [2] and NATPOL [3] studies, dyslipidemia is the most common factor contributing to the development of ischemic heart disease. It is estimated that over 16 million people in Poland suffer from this disease.

Decreasing the risk of complications of dyslipidemia and other cardiovascular risk factors continues to be a controversial topic in scientific research. The results of studies demonstrate that modern medicine has at its disposal efficient, safe, and relatively cheap hypolipidemic drugs [4, 5]. Among those drugs, 3-hydroxy-3-methyl-glutaryl-CoA reductase inhibitors, i.e. statins, play the most important role in the prevention of ischemic heart disease [6]. Despite their undisputed importance in modern cardiological pharmacotherapy, in everyday clinical practice, the use of statins is still below the expected level $[7,8]$.

This study, the 3ST-POL [9] (Standards of use of statins in Poland) study, and other country-wide studies conducted

Address for correspondence: Daniel Śliż, 3rd Department of Internal Medicine and Cardiology, Medical University of Warsaw, Solec 93, 00-382 Warsaw, Poland E-mail: sliz.daniel@gmail.com

Received: 4 April 2013; accepted: 3 January 2014 in Poland as part of the EUROASPIRE [10] and POLCARD SPOK [11] programs, provide unequivocal proof that the use of statins in the treatment of dyslipidemia is insufficient in outpatient care in Poland; however, as of today, there are no data with regard to the efficacy of statin treatment in patients in different regions of Poland. The purpose of the 3ST-POL study was to demonstrate the differences in treatment of dyslipidemia in various regions of Poland.

\section{OBJECTIVE}

The purpose of this study was to evaluate the efficacy of achieving therapeutic goals of total cholesterol (TC) and lowdensity lipoprotein (LDL cholesterol) levels among patients treated with statins as an outpatient in various regions of Poland.

\section{MATERIALS AND METHODS}

This study included 49,950 Polish patients who were treated on an outpatient basis in 2008. The patients were treated by GPs, cardiologists and diabetologists. The consecutive patients, who met both the inclusion and exclusion criteria, were enrolled to the study. The participants were selected based on the following criteria: treatment with statins for a 
minimum of 3 months before taking part in the study, aged between 40 and 85 years old, and consent to participate in the study. Other medical treatments did not constitute exclusion from the study. The research tool used in this study was a survey. The survey used, detailed inclusion criteria, and a description of the study group were included in a previous publication

To evaluate the efficacy of treatment of patients in various regions of the country, the provinces of Poland were divided into 4 regions: the Northwest (NW) region (West Pomeranian, Lubusz, Greater Poland, Pomeranian, and Kuyavian-Pomeranian provinces), the Southwest (SW) region (Lower Silesian, Opole, and Silesian, Łódź provinces), the Southeast (SE) region (Świętokrzyskie, Lesser Poland, Podkarpackie, and Lublin provinces), and the Northeast (NE) region (Masovian, Podlaskie, and Warmian-Masurian provinces).

The goals for lipid treatment were defined according to ESC (European Society of Cardiology)/EAS (European Atherosclerosis Society) guidelines of 2007 [12] (Table 1).

Table 1. ESC guidelines for levels of individual lipid fractions

\begin{tabular}{|c|c|c|}
\hline Cholesterol fractions & General population & High risk patients* \\
\hline Total cholesterol & $<190 \mathrm{mg} / \mathrm{dl}<5 \mathrm{mmol} / \mathrm{l}$ & $\begin{array}{l}<175 \mathrm{mg} / \mathrm{dl}^{* *} \\
<4.5 \mathrm{mmol} / \mathrm{l}\end{array}$ \\
\hline LDL & $\begin{array}{l}<115 \mathrm{mg} / \mathrm{dl} \\
<3 \mathrm{mmol} / \mathrm{l}\end{array}$ & $\begin{array}{c}<100 \mathrm{mg} / \mathrm{dl}^{* * *}<2.5 \\
\mathrm{mmol} / \mathrm{l}\end{array}$ \\
\hline TG & \multicolumn{2}{|c|}{$\begin{array}{l}<150 \mathrm{mg} / \mathrm{dl} \\
<1.7 \mathrm{mmol} / \mathrm{l}\end{array}$} \\
\hline HDL (females) & \multicolumn{2}{|c|}{$\begin{array}{c}>45 \mathrm{mg} / \mathrm{dl} \\
>1.2 \mathrm{mmol} / \mathrm{l}\end{array}$} \\
\hline HDL (males) & \multicolumn{2}{|c|}{$\begin{array}{c}>40 \mathrm{mg} / \mathrm{dl} \\
>1.0 \mathrm{mmol} / \mathrm{l}\end{array}$} \\
\hline
\end{tabular}

* confirmed CVD, DM, SCORE $\geq 5$

*** $<155 \mathrm{mg} / \mathrm{dl}$ if attainable

*** $<80 \mathrm{mg} / \mathrm{dl}$ if attainable

Statistical analysis. The data gathered in the course of the study is presented by means of standard descriptive statistics: means and standard deviations, medians and quartiles for continuous data and frequency tables for discrete data.

ANOVA was performed and multiple pairwise comparisons completed with post hoc Tukey test (alpha $=0.05$ ).

The achievement of lipid profile levels consistent with the applicable ESC guidelines of 2007 was the defining point for effective treatment.

A significance level of 0.05 was adopted for analysis, which was conducted in Stata v10 software [cf: Stata Statistical Software: Release 10, College Station, TX, Stata Corporation].

A more detailed list of the statistical methods used in data analysis was described and published in the journal, Polish Cardiology (Kardiologia Polska) [13].

\section{RESULTS}

The largest group of participants came from the SW region, $31.1 \%$ of the total study group. The smallest groups came from the SE and NE regions, $20 \%$ and $20.5 \%$, respectively (Tab. 3). Patients from the Silesian and Masovian provinces constituted the largest percentage of participants (14.8\% and $14.2 \%$, respectively), and patients from the Świętokrzyskie
Table 2. Geographical distribution of participants

\begin{tabular}{|c|c|c|}
\hline Province: & $\mathrm{n}$ & $\%$ \\
\hline \multicolumn{3}{|c|}{ Northwest (NW) Region } \\
\hline total & 13,665 & 28.9 \\
\hline Kuyavian-Pomeranian & 2,949 & 6.2 \\
\hline Pomeranian & 3,173 & 6.7 \\
\hline Lubusz & 1,308 & 2.8 \\
\hline Greater Poland & 4,115 & 8.7 \\
\hline West Pomeranian & 2,120 & 4.5 \\
\hline \multicolumn{3}{|l|}{ Southwest (SW) Region } \\
\hline total & 14,825 & 31.1 \\
\hline Lower Silesian & 2,957 & 6.2 \\
\hline Łódź & 3,725 & 7.7 \\
\hline Opolskie & 1,143 & 2.4 \\
\hline Silesian & 7,000 & 14.8 \\
\hline \multicolumn{3}{|l|}{ Southeast (SE) Region } \\
\hline total & 9,248 & 20 \\
\hline Lublin & 2,248 & 4.7 \\
\hline Lesser Poland & 4,017 & 8.5 \\
\hline Podkarpackie & 1,831 & 3.9 \\
\hline Świętokrzyskie & 1,152 & 2.4 \\
\hline \multicolumn{3}{|l|}{ Northeast (NE) Region } \\
\hline total & 9,656 & 20.50 \\
\hline Masovian & 6,711 & 14.2 \\
\hline Podlaskie & 1,259 & 2.7 \\
\hline Warmian-Masurian & 1,686 & 3.6 \\
\hline
\end{tabular}

and Opole provinces constituted the smallest percentage of participants (both constituting 2.4\% of the study group).

In all regions included in the study, the majority of patients were women and the age group most represented was 65 years and older. Patients younger than 49 years constituted the smallest percentage of all participants. In all regions, patients with secondary school and vocational education constituted the largest percentage of participants.

Among the participants in all regions, hypercholesterolemia was diagnosed, on average, 12 months before the beginning of the study. Patients who were diagnosed with hypercholesterolemia within less than 6 months of qualifying for the study constituted the smallest group of participants (Tab. 3).

The study group also had similar profiles with regard to the occurrence of risk factors, such as ischemic heart disease, history of heart attack, history of brain stoke, and type 2 diabetes.

Achievement of therapeutic goals (Tab. 4) of total cholesterol in all 4 regions was observed in less than $10 \%$ of the patients. The largest percentage of successful achievement of target total cholesterol was in patients of the NE region $(9.88 \%)$, and the smallest percentage observed in patients of the NW region $(6.76 \%)(\mathrm{p}<0.01)$. The study demonstrated a statistically significant higher rate of achieving target total cholesterol by cardiologists, as opposed to GPs in all regions. For diabetologists, a significantly higher rate of achieving the target total cholesterol was only observed in the SE region.

Similar to results for total cholesterol, the largest percentage of patients whose target concentration LDL-fraction was 
Table 3. Overview of participants by region

\begin{tabular}{|c|c|c|c|c|c|c|c|c|}
\hline \multirow[t]{2}{*}{ Region } & \multicolumn{2}{|c|}{ NW } & \multicolumn{2}{|c|}{ SW } & \multicolumn{2}{|c|}{ SE } & \multicolumn{2}{|c|}{$\mathrm{NE}$} \\
\hline & $\mathrm{n}$ & $\%$ & $\mathrm{n}$ & $\%$ & $\mathrm{n}$ & $\%$ & $n$ & $\%$ \\
\hline \multicolumn{9}{|l|}{ Gender } \\
\hline Women & 7,165 & 50.85 & 8,062 & 53.87 & 4,915 & 52.37 & 5,417 & 55.74 \\
\hline Men & 6,925 & 49.15 & 6,905 & 46.13 & 4,470 & 47.53 & 4,302 & 44.26 \\
\hline \multicolumn{9}{|l|}{ Age } \\
\hline $18-49$ & 2,268 & 16.55 & 2,184 & 15.04 & 1,155 & 12.55 & 1,423 & 14.95 \\
\hline $50-54$ & 2,615 & 19.08 & 2,335 & 16.08 & 1,510 & 16.41 & 1,618 & 17 \\
\hline $55-59$ & 2,633 & 19.21 & 2,802 & 19.3 & 1,643 & 17.86 & 1,660 & 17.44 \\
\hline $60-64$ & 2,345 & 17.11 & 2,455 & 16.91 & 1,709 & 18.58 & 1,522 & 15.99 \\
\hline $65+$ & 3,847 & 28.06 & 4,745 & 32.68 & 3,183 & 34.6 & 3,294 & 34.61 \\
\hline \multicolumn{9}{|l|}{ Education } \\
\hline Primary & 158 & 12.01 & 1,655 & 12.08 & 1,190 & 13.86 & 1,187 & 13.31 \\
\hline Vocational & 4,025 & 30.59 & 4,022 & 29.53 & 2,378 & 27.69 & 2,133 & 23.91 \\
\hline Secondary & 5,336 & 40.55 & 5,629 & 41.07 & 3,519 & 40.98 & 384 & 43.04 \\
\hline High & 2,218 & 16.86 & 2,399 & 17.5 & 1,501 & 17.48 & 1,761 & 19.74 \\
\hline \multicolumn{9}{|c|}{ Duration of hypercholesterolemia } \\
\hline Last 6 months & 1,724 & 12.7 & 2,247 & 15.19 & 1,211 & 13.26 & 1,302 & 13.56 \\
\hline $6-12$ months & 2,534 & 18.66 & 2,597 & 17.56 & 1,491 & 16.33 & 1,905 & 19.84 \\
\hline $1-3$ years & 3,458 & 25.46 & 3,858 & 26.09 & 2,302 & 25.21 & 243 & 25.31 \\
\hline $3-5$ years & 2,792 & 20.56 & 2,686 & 18.16 & 1,803 & 19.75 & 1,757 & 18.3 \\
\hline $\begin{array}{l}\text { More than } 5 \\
\text { years }\end{array}$ & 3,072 & 22.62 & 3,402 & 23 & 2,324 & 25.45 & 2,207 & 22.99 \\
\hline
\end{tabular}

Diagnosed Ischaemic Heart Disease

\begin{tabular}{lcccccccc}
\hline No & 7,796 & 57.68 & 7,617 & 52.23 & 422 & 46.5 & 5,144 & 54.86 \\
\hline Yes & 572 & 42.32 & 666 & 47.77 & 4,855 & 53.5 & 4,232 & 45.14
\end{tabular}

Heart attack in the past

\begin{tabular}{lllllllll}
\hline No & 10,336 & 78.59 & 1,133 & 80.71 & 6,813 & 78.84 & 7,333 & 81.17 \\
\hline
\end{tabular}

\begin{tabular}{lllllllll}
\hline Yes & 2,816 & 21.41 & 2,708 & 19.29 & 1,829 & 21.16 & 1,701 & 18.83
\end{tabular}

Stroke in the past

\begin{tabular}{lllllllll}
\hline No & 11,507 & 88.12 & 12,567 & 90.15 & 7,785 & 91.29 & 8230 & 91.82 \\
\hline
\end{tabular}

\begin{tabular}{lllllllll}
\hline Yes & 1,552 & 11.88 & 1,373 & 9.85 & 743 & 8.71 & 733 & 8.18
\end{tabular}

Diagnosed type 2 diabetes

\begin{tabular}{lllllllll} 
No & 8,729 & 64.9 & 9,884 & 68.89 & 5,814 & 65.95 & 6,357 & 68.79 \\
\hline
\end{tabular}

$\begin{array}{lllllllll}\text { Yes } & 4,720 & 35.1 & 4,464 & 31.11 & 3,002 & 34.05 & 2,884 & 31.21\end{array}$

achieved was in patients from the NE region, and the lowest efficacy of treatment was observed in patients from the NW region $(p<0.05)$. The differences in rates of achieving the target LDL plasma concentration among the patients treated by cardiologists, in comparison to GPs, were statistically significant. In all regions, a nominal number of cases achieving therapeutic goals for target LDL was higher for diabetologists, in comparison to GPs, although the difference was statistically significant only in the NE region.

The mean dosages of statins (atorvastatin and simvastatin) most commonly used by doctors of different specializations are presented in Table 5. The highest dosages of atorvastatin were recommended in the NW region and the lowest in the $\mathrm{NE}$ region $(\mathrm{p}<0.01)$. For simvastatin, the highest doses were used in the NE region and the lowest in the SE region $(\mathrm{p}<0.01)$. Cardiologists used higher dosages of both statins in comparison to GPs in all regions except the SW region.
Table 4. The achievement of therapeutic goals of LDL and TC concentrations by doctors of different specializations by region of Poland

\begin{tabular}{|c|c|c|c|c|c|c|c|c|c|}
\hline & & \multicolumn{2}{|c|}{ NW Region } & \multicolumn{2}{|c|}{ SW Region } & \multicolumn{2}{|c|}{ SE Region } & \multicolumn{2}{|c|}{ NE Region } \\
\hline & & No & Yes & No & Yes & No & Yes & No & Yes \\
\hline \multicolumn{10}{|l|}{ TC } \\
\hline \multirow[b]{2}{*}{ GF } & $\mathrm{n}$ & 10,154 & 610 & 11,227 & 888 & 5,928 & 422 & 7,192 & 702 \\
\hline & $\%$ & 94.33 & 5.67 & 92.67 & 7.33 & 93.35 & 6.65 & 91.11 & 8.89 \\
\hline \multirow{2}{*}{$\begin{array}{l}\text { Cardio- } \\
\text { logist }\end{array}$} & $\mathrm{n}$ & 1,709 & 215 & 1,741 & 245 & 1922 & 207 & 1,191 & 192 \\
\hline & $\%$ & 88.83 & $11.17 \wedge$ & 87.66 & $12.34 \wedge$ & 90.28 & $9.72^{\wedge \wedge}$ & 86.12 & $13.88^{\wedge}$ \\
\hline \multirow{2}{*}{$\begin{array}{l}\text { Diabeto- } \\
\text { logist }\end{array}$} & $\mathrm{n}$ & 552 & 75 & 531 & 68 & 641 & 102 & 321 & 60 \\
\hline & $\%$ & 88.04 & 11.96 & 88.65 & 11.35 & 86.27 & $13.73^{\wedge \wedge}$ & 84.25 & 15.75 \\
\hline \multirow{2}{*}{ Total } & $\mathrm{n}$ & 12,415 & 900 & 13,499 & 1201 & 8,491 & 731 & 8704 & 954 \\
\hline & $\%$ & 93.24 & 6.76 & 91.83 & 8.17 & 92.07 & 7.93 & 90.12 & $9.88^{*}$ \\
\hline \multicolumn{10}{|l|}{ LDL } \\
\hline \multirow{2}{*}{ GP } & $\mathrm{n}$ & 6,985 & 649 & 7,964 & 977 & 3,867 & 463 & 5,297 & 774 \\
\hline & $\%$ & 91.50 & 8.50 & 89.07 & 10.93 & 89.31 & 10.69 & 87.25 & 12.75 \\
\hline \multirow{2}{*}{$\begin{array}{l}\text { Cardio- } \\
\text { logist }\end{array}$} & $\mathrm{n}$ & 1,318 & 215 & 1,346 & 245 & 1,270 & 239 & 926 & 175 \\
\hline & $\%$ & 85.98 & $14.02^{\wedge}$ & 84.60 & $15.40^{\wedge}$ & 84.16 & $15.84^{\wedge}$ & 84.11 & $15.89^{\wedge}$ \\
\hline \multirow{2}{*}{$\begin{array}{l}\text { Diabeto- } \\
\text { logist }\end{array}$} & $\mathrm{n}$ & 423 & 55 & 379 & 87 & 440 & 92 & 169 & 71 \\
\hline & $\%$ & 88.49 & 11.51 & 81.33 & 18.67 & 82.71 & 17.29 & 70.42 & $29.58^{\wedge \wedge}$ \\
\hline \multirow{2}{*}{ Total } & $\mathrm{n}$ & 8,726 & 919 & 9,689 & 1309 & 5,577 & 794 & 6392 & 1,020 \\
\hline & $\%$ & 90.47 & 9.53 & 88.10 & 11.90 & 87.54 & 12.46 & 86.24 & $13.76^{* *}$ \\
\hline
\end{tabular}

Statistical significance is marked by * $p<0.01$ and $* * p<0.05$ among total mean dosages of two statins used by doctors of different specializations.

Statistical significant difference between achieving of therapeutic goals of LDL and TC by cardiologists or diabetologists vs. GP's in different regions $\wedge p<0.01$ and $\wedge \wedge p<0.05$.

Table 5. Mean dosages $(\mathrm{mg})$ of the two statins most commonly used by doctors of different specializations by region of Poland

\begin{tabular}{lcccccccc}
\hline & \multicolumn{2}{c}{ NW Region } & \multicolumn{2}{c}{ SW Region } & \multicolumn{2}{c}{ SE Region } & \multicolumn{2}{c}{ NE Region } \\
\hline & $\begin{array}{l}\text { Atorva } \\
\text { statin }\end{array}$ & $\begin{array}{c}\text { Simva } \\
\text { statin }\end{array}$ & $\begin{array}{c}\text { Atorva } \\
\text { statin }\end{array}$ & $\begin{array}{c}\text { Simva } \\
\text { statin }\end{array}$ & $\begin{array}{c}\text { Atorva } \\
\text { statin }\end{array}$ & $\begin{array}{c}\text { Simva } \\
\text { statin }\end{array}$ & $\begin{array}{c}\text { Atorva } \\
\text { statin }\end{array}$ & $\begin{array}{l}\text { Simva } \\
\text { statin }\end{array}$ \\
\hline GP & 21.06 & 24.48 & 20.76 & 23.87 & 19.89 & 22.78 & 20.06 & 25.45 \\
\hline $\begin{array}{l}\text { Cardio- } \\
\text { logist }\end{array}$ & $22.58^{\wedge \wedge}$ & $25.64^{\wedge}$ & 20.88 & 24.60 & $21.55^{\wedge}$ & $26.55^{\wedge}$ & $22.88^{\wedge \wedge}$ & $28.34^{\wedge}$ \\
\hline $\begin{array}{l}\text { Diabeto- } \\
\text { logist }\end{array}$ & 23.65 & 23.15 & 21.59 & 23.19 & 22.19 & 22.22 & 18.23 & 21.00 \\
\hline Total & $21.45^{*}$ & 24.62 & 20.81 & 23.97 & 20.53 & 23.62 & 20.36 & $25.82^{*}$
\end{tabular}

Statistical significance indicated by ${ }^{*} \mathrm{p}<0.01$ among total mean dosages of the two statins used by doctors of different specializations.

Statistical significant difference between dosages administered by cardiologist vs. GP's in different regions $\wedge p<0.01$ and $\wedge \wedge p<0.05$.

\section{DISCUSSION}

Statins play a key role in the treatment of dyslipidemia. Although alternative treatment options and adjuvants for statins have been actively studied in recent years, the role of statins in current cardiological treatment remains unchanged. Studies on the efficacy of prevention and treatment of diseases caused as a result of lipid disorders and inflammation, show strong proof of the efficacy of statins in decreasing cardiovascular risks with regard to both primary and secondary prevention.

To maximize the efficacy of treatment of lipid disorders, the European Society of Cardiology regularly publishes guidelines for therapeutic goals and the treatment of dyslipidemia [14]. In the presented study, to ensure the proper evaluation of efficacy of treatment, patient results were compared with guidelines from 2007. 
The participants in this study were patients whose treatment included the use of statins on an outpatient basis in Poland. The need for the use of statins and the increasing percentage of patients aged 60 years and older accounts for the frequent occurrence of risk factors and co-existing diseases among the study group. The rates of occurrence of ischemic heart disease, diabetes, and the number of patients who experienced a cardiovascular and/or cerebral-vascular event in the past were higher than for the general population in Poland. However, the data obtained in the study show no significant differences for various regions.

The difference in the success rate of achieving target total cholesterol between the NW region and the remaining regions was statistically significant. The lowest efficacy was observed in the NW region. A similar correlation was observed in achievement of recommended LDL-fraction concentrations. In the NW region, the large positive difference in achieving target therapeutic results of LDL and TC may be due to the influence of the Masovian province (69\%). The Masovian province has the highest urbanization rate in Poland and is the most economically developed in the region. These factors may directly contribute to the quality of life of the inhabitants and the education of both patients and doctors. Regarding the remaining regions, no evident correlation among regions was observed according to income.

The statins most commonly used in the study were atorvastatin and simvastatin. Rosuvastatin was not included in the study because it was not available on the Polish market at the time of the study. The correlation between mean dosages of the two most commonly used statins and the efficacy of treatment in various regions was not evident. This may be due to regional differences in compliance with the recommended treatment, as well as differences resulting from other factors that may have an impact on the results, e.g. cultural differences or differences in regional culinary traditions. Due to the nature of this study, the authors were unable to access the initial cholesterol levels in the studied regions, making it impossible to determine unequivocally the net efficacy of treatment in the study. However, a significant correlation between the above-mentioned factors was observed in the data analyzed for all the participating patients.

Among the participants in all regions, the dosages of statins used by cardiologists were significantly different from the dosages used by GPs, with the exception of dosages of simvastatin, recommended by cardiologists in the SW region. Evidently, this influenced the frequency of achieving therapeutic goals, both with regard to total cholesterol and LDL levels.

\section{CONCLUSIONS}

Significant differences with regard to achieving the target values of TC and LDL were observed in the study group. Based on the results of the study, it is impossible to determine the causes of the described differences, as they are likely to be complex.
It is essential to discuss the limitations of this study to ensure proper interpretation of the reported results. These limitations were published in the journal Kardiologia Polska (Polish Cardiology). Our publication lists only a number of the most important study limitations. This study was conducted using a survey, and some of the obtained data were of a declarative nature. It is possible that the dosages of drugs were overestimated, as adherence and compliance with the recommended treatment were not included in the study.

\section{REFERENCES}

1. Dane statystyczne dotyczące przyczyn zgonu. http://epp.eurostat. ec.europa.eu/statistics_explained/index.php/Causes_of_death_ statistics/pl (access: 10.02.2013).

2. Piwonska A, Piotrowski W, Broda G. Ten-year risk of fatal cardiovascular disease in the Polish population and medical care. Results of the WOBASZ study. Kardiol Pol. 2010; 68: 672-677.

3. Jaki jest stan zdrowia Polaków według NATPOL 2011? http:// www.termedia.pl/Jaki-jest-stan-zdrowia-Polakow-wedlugNATPOL-2011-,4624.html (access: 10.02.2013).

4. Baigent C, Keech A, Kearney PM, Blackwell L, Buck G, Pollicino C, et al. Efficacy and safety of cholesterol - lowering treatment: prospective meta - analysis of data from 90,056 participants in 14 randomised trials of statins. Lancet 2005; 366: 1267-78. doi:10.1016/S0140 - 6736(05)67394 - 1 PMID:16214597.

5. Heart Protection Collaborative Group. MRC/BHF Heart Protection Study of cholesterol lowering with simvastatin in 20,536 high-risk individuals: a randomised placebo-controlled trial. Lancet 2002; 360(9326): 7-22.

6. Gotto AM Jr, Moon JE. Recent clinical studies of the effects of lipidmodifying therapies Am J Cardiol. 2012; 110(1 Suppl): 15A-26A.

7. Cooney MT, Kotseva K, Dudina A, De Backer G, Wood D, Graham I. Determinants of risk factor control in subjects with coronary heart disease: a report from the EUROASPIRE III investigators. Eur J Prev Cardiol. 2012 Apr 18.

8. Bhatt DL, Steg PG, Ohman EM, et al. International prevalence, recognition, and treatment of cardiovascular risk factors in outpatients with atherothrombosis. JAMA 2006; 295(2): 180-189.

9. Sliz D, Mamcarz A, Filipiak KJ, Siebert J, Naruszewicz M. 3ST-POL trial: standards of statin use in Poland in the context of the European Society of Cardiology guidelines. Pol Arch Med Wewn. 2010; 120(9): 328-33.

10. Kotseva K, Wood D, De Backer G, et al. Cardiovascular prevention guidelines in daily practice: a comparison of EUROASPIRE I, II, and III surveys in eight European countries. Lancet 2009; 373: 929-940.

11. Filipiak K, Pietrasik A, Starczewska M, et al. Polish country-wide, multicentre system of monitoring the standard of primary cardiological care in GP surgeries (POLCAD - SPOK): methods used during realization of the programme. Kardiol Pol. 2006; 64(8): S167-S171.

12. Graham I, Atar D, Borch-Johnsen K, Boysen G, Burell G, Cifkova R, Dallongeville J, De Backer G, Ebrahim S, Gjelsvik B, et al. European guidelines on cardiovascular disease prevention in clinical practice: Fourth Joint Task Force of the European Society of Cardiology and other societies. Eur J Cardiovasc Prev Rehabil. 2007; 14(Suppl 2): S1-S113.

13. Sliz D, Filipiak KJ, Naruszewicz M, Siebert J, Mamcarz A. Standard of statin usage in Poland in high-risk patients: 3ST-POL study results. Kardiol Pol. 2013; 71(3): 253-259.

14. Fifth Joint Task Force of the European Society of Cardiology. European Guidelines on cardiovascular disease prevention in clinical practice: the Fifth Joint Task Force of the European Society of Cardiology and Other Societies on Cardiovascular Disease Prevention in Clinical Practice (constituted by representatives of nine societies and by invited experts). Eur J Prev Cardiol. 2012; 19(4): 586-667. 